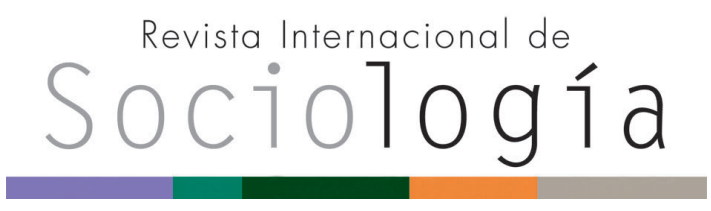

Revista Internacional de Sociología RIS

vol. 75 (4), e080, octubre-diciembre, 2017, ISSN-L:0034-9712

doi: http://dx.doi.org/10.3989/ris.2017.75.4.17.06

\title{
ENERGÍA HUILLICHE Experimentos en integración y disensos ontológicos en un parque eólico
}

\section{HUILLICHE ENERGY \\ Experiments in integration and ontological disagreements in a wind farm}

\author{
Manuel TiRoni \\ metironi@uc.cl \\ ORCID iD: http://orcid.org/0000-0003-2733-8071 \\ JoRgELINA SANNAZZARO \\ Universidad Alberto Hurtado, Chile \\ sannazzaro.jorgelina@gmail.com \\ ORCID iD: http://orcid.org/0000-0003-1223-4253
}

Pontificia Universidad Católica de Chile, Chile. / Núcleo Milenio de Investigación en Energía y Sociedad, Chile

Cómo citar este artículo / Citation: Tironi, M. y J. Sannazzaro. 2017. "Energía huilliche. Experimentos en integración y disensos ontológicos en un parque eólico". Revista Internacional de Sociología 75 (4): e080. doi: http://dx.doi.org/10.3989/ris.2017.75.4.17.06

\section{Resumen}

La isla de Chiloé, en el sur de Chile, fue el escenario de un proyecto sin precedentes: el desarrollo de un parque eólico donde la comunidad Huilliche, pueblo ancestral de la zona, sería propietaria del proyecto. Con el sostén del Banco Interamericano de Desarrollo, el proyecto buscaba apoyar la transición hacia una matriz eléctrica más limpia; pero sobre todo integrar de manera definitiva a los pueblos originarios en la sociedad chilena a través de su participación en empresas económicas de alto valor. Siguiendo la idea de la participación ciudadana como experimentación, en este artículo seguimos etnográficamente el proceso de gestación, desarrollo y posterior fracaso del proyecto. El caso, argumentamos, permite reflexionar sobre los riesgos de agresión cultural a los que están expuestos los experimentos participativos, pero también sobre su capacidad para abrir espacios productivos de especulación identitaria, ética y política. Acuñamos la figura de los "disensos ontológicos" para mostrar las ambivalencias de los experimentos participativos y para debatir sobre el futuro de la implicación de los pueblos originarios en el desarrollo eléctrico chileno.
\end{abstract}

\section{Palabras Clave}

Energía eólica; Participación; Política ontológica;

Pueblos indígenas.
Copyright: (C) 2017 CSIC. Este es un artículo de acceso abierto distribuido bajo los términos de la licencia Creative Commons Attribution (CC BY) España 3.0.

Recibido: 15/12/2016. Aceptado: 10/07/2017.

\section{Abstract}

The island of Chiloé, in southern Chile, was the miseen-scene of an unprecedented project: the development of a wind farm in which the Hulliche community, the ancestral people of the area, would own and run the operation. With the support of the Inter-American Development Bank, the aim of the project was the production of sustainable and renewable energies, but more importantly the integration of indigenous communities into the Chilean society via their participation in a high-value economic enterprise. Drawing on the idea of citizen participation as a form of experimentation, in this article we follow ethnographically the process of incubation, development and failure of this project. The case, we argue, allows a reflection about the risk of cultural aggression embedded in participatory experiments, but also about their capacities to crack open productive spaces for identity, political and ethical speculation. We coin the term "ontological disagreements" to indicate the ambivalences of participatory experiments and to debate about the future of indigenous engagement in energy projects.

\section{KeYWORDS}

Indigenous People; Ontological politics; Participation; Wind Power. 


\section{INTRODUCCIÓN: IMAGINANDO UNA ENERGÍA HUILLICHE}

Isla grande de Chiloé, 21 de enero del 2016. Después de varias conversaciones, finalmente se realizaba el encuentro entre representantes del Banco Interamericano de Desarrollo (BID) y diversos lonkos ${ }^{1}$. La reunión tenía lugar en la comunidad de Chanquín-Palihue, ubicada a pocos kilómetros del parque nacional Cucao. El escenario era impactante. La fulgurante belleza natural, la proximidad del mar, las arenas blancas extendiéndose por la costa, el ruido del oleaje y la potencia del viento le daban al encuentro un dramatismo acorde con la importancia política del evento.

Sentados en torno al fogón, el espacio de reunión tradicional en el mundo mapuche, el encuentro era un modo de coronar los esfuerzos realizados por el Programa de Apoyo al Emprendimiento Indígena (PAEI) y la comunidad de Chanquín-Palihue para la creación de un parque eólico en territorio huilliche ${ }^{2}$. En el encuentro también participaba Sergio Cuyul, líder huilliche e impulsor del proyecto. La posibilidad de desarrollar proyectos económicos dentro de un esquema de mercado con la participación de comunidades indígenas, dos fuerzas que en modelos extractivistas como el chileno han estado siempre encontradas, generaba expectación. Además, la reunión en Chanquín-Palihue coincidía con el seminario de planificación que los ejecutivos del BID realizan anualmente, y que llevan a cabo en alguno de los países beneficiarios de sus programas para aprovechar y ver 'sobre el terreno' su diseño, desarrollo o implementación. La puesta en escena en ChanquínPalihue era, por tanto, también una forma de demostración y validación. Junto al Banco Mundial, la Organización Mundial de Comercio y el Fondo Monetario Internacional, el BID ha sido crucial en la instalación de un modelo económico abierto y de mercado en América Latina. El PAEI es, evidentemente, parte de dicha agenda, agenda que requiere continua justificación. Y el encuentro en Chanquín-Palihue podía leerse en esa clave. Frente a los lonkos y la fuerza del océano Pacífico, el fogón convocaba a los ejecutivos del BID para discutir y planificar la construcción de un parque eólico en Chanquín-Palihue, pero también para visibilizar, confirmar y celebrar las prácticas de esta organización internacional.

Por parte del mundo mapuche, la reunión en Chanquín-Palihue también estaba cubierta por cierta expectación. El encuentro era una oportunidad para reunir a lonkos de diversas comunidades del país que habían sido previamente contactadas por el BID para impulsar experiencias similares a las de Chanquín-Palihue. La posibilidad de imaginar un parque eólico con participación económica de comunidades indígenas se convirtió durante el encuentro en un emblema: la posibilidad de soñar emprendimientos económicos indígenas no solo para Chiloé, sino tam- bién para el resto de las comunidades presentes. La posibilidad, puesto de otro modo, de invocar una nueva subjetividad mapuche, o a un mapuche que, sin perder su identidad, se integraría activamente a la vida económica formal, al mercado y, aunque no se vio desde el comienzo, al Estado chileno.

El hecho de que esta posibilidad fuese movilizada a través de un proyecto de energía eólica cubría al proyecto de un significado adicional. Primero, porque la conversión del pueblo mapuche en actor económico se hacía a través de una tecnología que ha vehiculizado las expectativas ( $y$ ansiedades) en torno a la sustentabilidad, el desarrollo local y el cuidado ecológico. La transición hacia energías más sustentables y renovables es uno de los experimentos "a la intemperie" más grande que hayamos visto (Gross 2015), y su despliegue viene aparejado con promesas de todo tipo. En este sentido, a través del desarrollo de un parque eólico la comunidad mapuche era invitada a sumarse a un Chile postindustrial que apostaba por el respeto a la naturaleza y a la solidaridad intergeneracional. Y segundo, porque en la última década los proyectos de generación eléctrica en el sur de Chile han chocado frontalmente con comunidades mapuche que ven en estas intervenciones un ataque, el final, a sus mundos y ecologías. La invitación era, por tanto, a inaugurar una nueva fase del modelo extractivista chileno.

En suma, lo que el PAEI permitía, y que la puesta en escena del fogón dramáticamente performaba, no era solo la posibilidad de implementar un parque eólico en Chanquín-Palihue. Era también la posibilidad de integrar de otra manera y en otros espacios al mundo indígena. El proyecto era ante todo un experimento social que imaginaba a un huilliche plenamente implicado y protagonista de un nuevo capitalismo más verde, local y sustentable. Lo que se jugaba esa tarde en Chanquín-Palihue, por tanto, no era la ejecución de un proyecto de energía, sino la demostración de que se podía hacer otra energía, una energía huilliche: un proyecto competitivo enmarcado dentro de los requerimientos de una economía capitalista, pero que ubicaba a las comunidades huilliche como protagonistas del proceso, implicándolas activamente dentro de un área de desarrollo clave para Chile.

Siguiendo las perspectivas de los estudios en ciencia, tecnología y sociedad (CTS), el presente artículo intenta pensar la experiencia de Chanquín-Palihue como una particular forma de experimentación (Shapin 1989; Muniesa and Callon 2007; Marres 2012), y más específicamente, como un particular experimento en integración. En integración porque el objetivo final del proyecto fue ensayar una nueva forma de incluir a comunidades huilliches en proyectos energéticos. Experimento porque el objeto de la participación en este ensayo, lejos de ser una realidad preexistente, fue provocado ontológicamente en un proceso inventivo que tuvo, como veremos, relevantes alcances políticos. 
Mapa 1.

Ubicación de Chiloé y zona de Chanquín-Palihue.

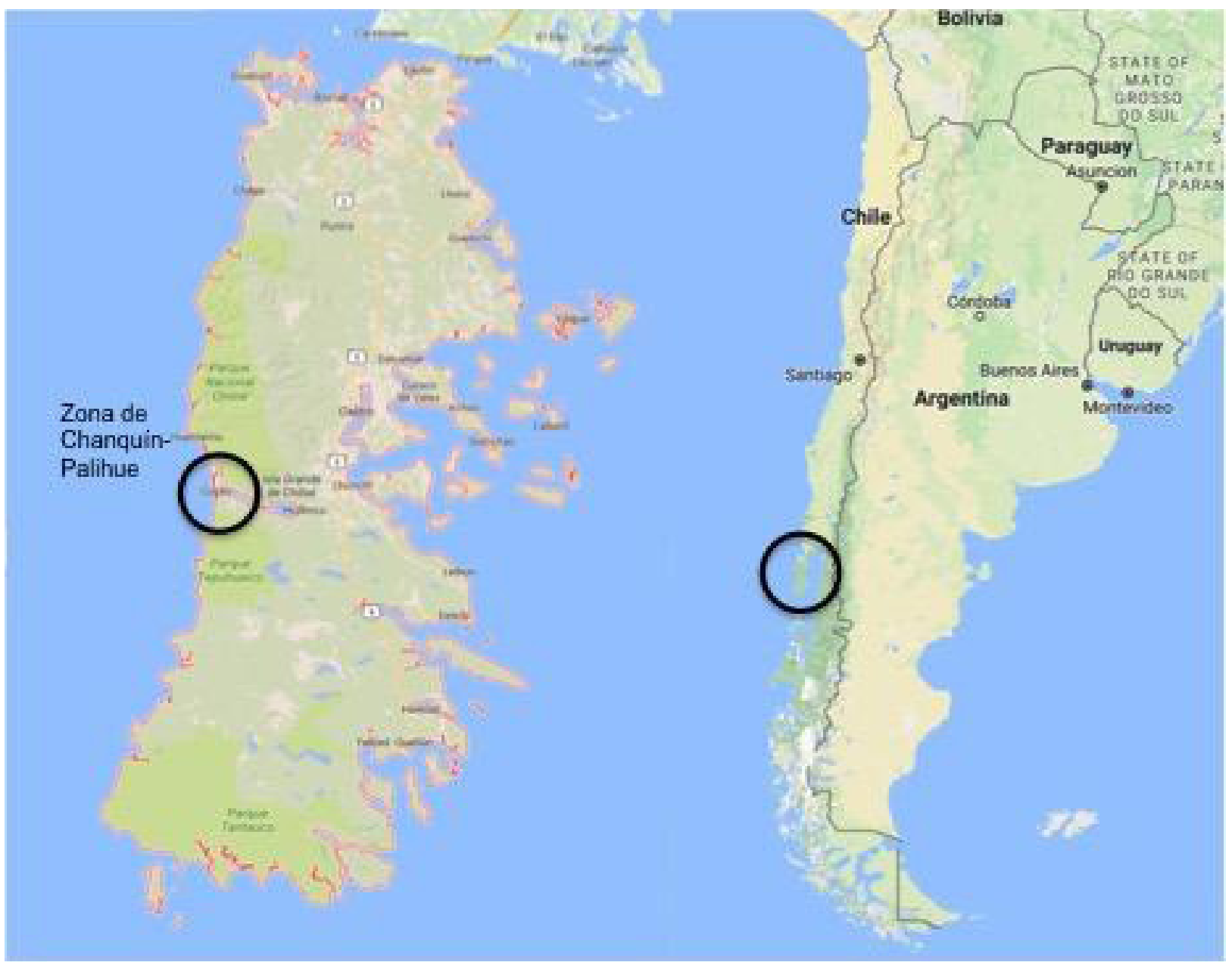

Fuente: confeccionado por autores a partir de Google Maps.

En efecto, llamamos experimento a lo sucedido en Chanquín-Palihue porque, primero, se trató de un proyecto cuyo objeto no precedía, sino que fue constituido a la intemperie y tentativamente en el proceso mismo de exploración (cf. Latour 1988; Rheinberger 1997; Marres 2012; Tironi 2014). Concretamente, nos detendremos en la figura del "huilliche empresario", el objeto sobre el cual el proyecto se articulaba y que se erguía, al mismo tiempo, como la condición que tenía que cumplirse para el éxito de este. Como veremos, la condición fue difícil de cumplir -el huilliche empresario fue más esquivo de lo esperado- y por tanto el objetivo del proyecto -la constitución de un nuevo huilliche integrado al sistema capitalistano se cumplió. El proyecto, de hecho, fracasó, entre otras razones porque el experimento fue resistido por una realidad más recalcitrante de lo planificado. En este artículo nos detenemos en las múltiples formas en que ontologías divergentes, la imaginada por el BID, por un lado, y la ejecutada por los propios vecinos de Chanquín-Palihue, por el otro, que colisionaron sin solución de continuidad.
Pero el experimento también abrió la posibilidad de repensar qué es exactamente lo huilliche en Chiloé. O mejor dicho, el proyecto, con todas sus carencias y agresiones, permitió abrir lo huilliche como y desde una otredad. Y esta es la segunda lectura del proyecto en tanto arreglo experimental: una iniciativa que tuvo la capacidad de abrir espacios de incertidumbre ontológica, y por tanto de provocar alternativas éticas que obligaron a ralentizar la acción y el pensamiento (Stengers 2005). En el caso de Chanquín-Palihue el proyecto creó las condiciones para que la naturaleza de lo "huilliche" y lo "indígena" fuese problematizada y expandida; por tanto, para abrir la posibilidad de imaginar otras formas de existencia y de potencialidad ético-política. Experimento, entonces, en el sentido de un momento generativo de invención y de re-repartición de lo sensible (Rancière 1996; Deleuze y Guattari 2000).

El objetivo de este artículo es, por tanto, explorar todas las consecuencias del programa experimental de integración desplegado en Chanquín-Palihue para así expandir la figura de la experimentalización 
con lo que llamamos disensos ontológicos. Alejándonos de perspectivas postfoucaulteanas, queremos pensar este experimento en integración como un proceso de sometimiento y normalización, pero también como un momento generativo de ampliación de lo posible: lo que buscamos es, precisamente, ver hasta qué punto las colisiones entre normalizaciones pueden crear posibilidades éticas. Como mostraremos, el experimento de Chanquín-Palihue estuvo plagado de contradicciones, descuidos y violencias de todo tipo. La historia del proyecto reenacta la tensión en el mundo indígena entre asimilacionismo y tradición o entre indígenas tradicionales y no tradicionales (Blaser 2016); y, por tanto, es en muchos sentidos una historia sobre los intentos, realizados incluso por miembros de las propias comunidades indígenas, parar "modernizar" identidades, prácticas y subjetividades. En este artículo cuestionamos ese intento de calibración. Calibrar lo huilliche en clave neoliberal para su integración en el modelo energético actual es una violencia colonial que queremos criticar y denunciar. Pero como una especie de situación cosmopolítica (Schillmeier 2011), el experimento también abrió la posibilidad de pensar en nuevos proyectos sociales en el Chile pos-Pinochet. Dicho de otro modo, nos interesa ser cuidadosos con la pregunta ontológica que el experimento posibilita precisamente en, y a través de, esos choques: queremos identificar qué sucede cuando la identidad huilliche -y las ontologías de una serie de fuerzas y objetos participando en el proyecto de Chanquín-Palihue-se vuelven un campo abierto a la exploración. Observando con atención el proyecto como una búsqueda experimental, nos preguntamos: ¿cuántas formas de ser huilliche coexisten en Chiloé? ¿De qué maneras estas formas, lejos de solaparse desproblematizadamente, colisionan en sus trayectorias y condiciones? ¿Pueden pensarse estos disensos ontológicos como espacios de creatividad y perseverancia ético-política y así invocar formas más sustentables y democráticas de ser, saber y habitar en el Chile actual?

La historia que contaremos en este artículo intentará hacerse cargo de estas preguntas. Y lo hará de forma etnográfica. Es decir, no intentaremos dibujar macro respuestas a las preguntas que nos guían, sino que nos detendremos en situaciones concretas en que lonkos, vecinos de Chanquín-Palihue, funcionarios públicos y ejecutivos del BID tuvieron que lidiar, ellos mismos, con los límites y posibilidades del experimento. Creemos que esta aproximación es fundamental cuando los conflictos energéticos, y particularmente los vinculados a pueblos indígenas, se multiplican en Chile (Tironi y Barandiaran 2014; Horvath-Kiss 2015). La participación de las comunidades en el diseño y la implementación de proyectos de generación eléctrica se ha convertido en un tema central tanto para el Estado como para la industria, toda vez que la sensación generalizada es que los esfuerzos en esta materia han fracasado. Este fra- caso es especialmente evidente en territorios indígenas en el sur de Chile, donde los proyectos energéticos han tenido que enfrentar el malestar cuajado durante siglos de agresión estatal-extractivista. Tal vez, especulamos, detenerse etnográficamente en la cotidianidad del experimento de Chanquín-Palihue permite identificar los elementos críticos detrás del fracaso de la participación ciudadana en proyectos energéticos, así como reconocer las alternativas que se incuban en proyectos como el de Chanquín-Palihue para la formulación de iniciativas energéticas más inclusivas.

El resto del artículo se organiza de la siguiente manera. En la próxima sección instalamos nuestro argumento en conversación con la literatura sobre experimentación y participación. En esta sección también discutimos la posibilidad de enriquecer este debate pensando la experimentalidad como un espacio de perseverancia ética a través de lo que llamamos disensos ontológicos. Invitando a la conversación a Elizabeth Povinelli (2011) y Jacques Derrida (1993), entre otros autores que han pensado la ética -y la políticacomo potencialidad, proponemos una extensión de las capacidades ontológicas de los experimentos. Luego presentamos nuestro material etnográfico. Este será desplegado basándose en dos historias, cada una discutiendo una dimensión de la capacidad experimental del proyecto. La primera narración se centra en los intentos del experimento por constituir su objeto -el huilliche empresario- y las múltiples maneras en que sus supuestos chocaron con lo que se encontró en terreno. Aquí exponemos los contornos empíricos de los disensos ontológicos que nos interesa debatir. La segunda historia, de tono más biográfico, se centra en la figura de Sergio Cuyul. Artífice del proyecto y personaje clave en la historia del experimento, Cuyul deja de manifiesto en su historia sus esfuerzos y sus conflictos con múltiples actores locales y nacionales. ¿Hasta qué punto el proyecto de Chanquín-Palihue abrió la posibilidad de experimentar lo que significa ser huilliche en la isla y, por tanto, creó un espacio de incertidumbre ontológica que pudo (debe) ser explorado políticamente? Para ser cuidadosos con la situación, y mantenernos con el problema (Haraway 2016), en esta sección nos volvemos retrospectivamente a la historia y trayectoria de Cuyul como una manera de ir entendiendo cómo se le da forma, lenta y contradictoriamente, a una promesa ontológica. Finalmente, concluimos reflexionando sobre el aporte del caso de Chanquín-Palihue al debate en los estudios CTS sobre las capacidades ontológicas de los experimentos, ubicando nuestros resultados en el marco de la transición hacia energías más limpias y renovables en Chile.

\section{DisenSOS ONTOLÓGICOS Y LA EXPERIMENTALIZACIÓN DE LA PARTICIPACIÓN}

En Enero 2016, conforme avanzaba el encuentro entre lonkos, la comunidad de Chanquín-Palihue y 
el BID se creaba y extendía una particular atmósfera afectiva. En la mañana, a la llegada de los representantes del BID, se ofreció una rogativa para pedir por el correcto desarrollo del encuentro. La ceremonia de petición estuvo a cargo de Augusto Nahuelpan Calfucurra, referente del Consejo de Lonkos del Pikunwillimapu. Nahuelpan viajó especialmente para el encuentro desde Lanco, a unos 300 kilómetros al norte de Chiloé. Le acompañaban el werken Jorge Avello, Anita Huincatripay, werken vocera de la comunidad La Unión, y Marcelo Quinchahuala, weche lonko -lonko joven- de una comunidad cercana a Loncoche. El acto se desarrolló en un terreno próximo al fogón. En el centro se instaló el encargado de la ceremonia frente a un cuenco con muday (bebida de maíz fermentado) y a su alrededor se distribuyeron los participantes. El sonido intenso y grave de la trutruca, instrumento ceremonial de viento tocado en esta ocasión por el weche lonko, impregnó, aún más, de dramatismo a la rogativa. Una vez que el lonko Nahuelpan hizo la rogativa en mapudungun, el acto ceremonial continuó solicitando a los presentes concentrarse en las peticiones y repetir al unísono algunas de las frases. Al finalizar, el jefe de la ceremonia, siempre con la asistencia del werken Jorge Avello y Anita Huincatripay, ofreció de beber muday a todos los asistentes, rellenándolo mientras se desplazaba entre nosotros. Era, sin duda, un momento de intensidad afectiva, y el ambiente de intimidad no dejaba indiferente a nadie: dos mundos, en muchos sentidos inconmensurables, eran convocados para establecer, en territorio indígena y bajo modos indígenas de hacer y conocer, una conversación que desafiaba siglos de violencia colonial.

A pocos metros, fuera de la sensación de unidad que la puesta en escena producía, las tensiones proliferaban. Algunas familias y lonkos provenientes de zonas aledañas de Chanquín-Palihue alegaron no estar lo suficientemente informados del proyecto y se negaron a participar del encuentro. Es más: de las 17 comunidades territoriales convocadas, tres manifestaron expresamente su oposición. Y exceptuando la comunidad de Chanquín-Palihue, las restantes comunidades nunca habían participado de las gestiones previas. Ya volveremos a este desencuentro. Por ahora basta indicar que, mientras desde el fogón y sus prácticas el encuentro ensayaba un espacio de diálogo y comunión, fuera de este la reunión se enactaba como un conflicto político. En la tarde, después de la rogativa, un grupo de disconformes con el procedimiento discutió acaloradamente a las puertas del recinto comunitario sin siquiera entrar a la reunión con el BID.

Otro grupo, perteneciente al Consejo Mayor de Caciques Huilliches de Chiloé, pidió conversar con el Jefe del equipo del PAEI en forma privada. En la conversación participaron Roberto Panichini, de la comunidad histórica de Chanquín en Chonchi y se- ñor cacique mayor del Consejo, junto con el joven Gérak Millalonko, quien pronto se titulará como abogado y actualmente se desempeña como maestro de paz del Consejo. Panchini y Millalonko abandonaron el fogón comunitario mucho antes de que terminara la jornada y sin que quedara claro para el resto de los asistentes cuál era la razón de su salida ni cuál era su posición con respecto al proyecto.

Algo que sí quedó claro fue la fragmentación de las distintas comunidades huilliche, incluso la franca oposición entre distintos grupos. Las diferentes trayectorias identitarias, cuajadas durante siglos de compleja relación entre lo indígena y lo chileno, también se volvieron evidentes esa mañana de verano. La mayoría de los huilliche chilotes presentes en el encuentro no hablaban mapudungun más allá de algunas palabras sueltas. Tampoco estaban familiarizados con los ritos ya que, según mencionaron, ese conocimiento "se ha ido perdiendo con el correr de los años". Mostrando los pliegues no siempre ordenados de lo "huilliche" en la isla, los comuneros de Chanquín-Palihue recibían las instrucciones de la ceremonia al igual que el resto de los asistentes "foráneos".

El proyecto eólico, en definitiva, puso de manifiesto que no estaba claro qué significaba ser "huilliche" en la isla, y que hacer participar a la comunidad huilliche de Chiloé requería, de alguna manera, inventarla: un proceso que, para ser exitoso, debía darle forma al sujeto que se haría participar en este.

EI PAEI puede ser entendido, por tanto, como un particular tipo de experimento. Los estudios CTS han investigado hace al menos tres décadas las características epistémicas y ontológicas de los experimentos no solo como modelo de generación de conocimiento científico, sino que, más ampliamente, como una manera de construir lo social en la sociedad contemporánea (Marres 2012; Lezaun et al. 2016). Desde los experimentos científicos en laboratorio hasta la experimentación en las artes, la figura del experimento se nutre de -y alimenta a- varias tradiciones experimentales. Todas ellas tienen en común la idea del experimento como un proceso que produce conocimiento de manera tentativa, exploratoria, en base al ensayo/error y sin saber de antemano lo que el procedimiento puede encontrar: el experimento es un proceso donde objetos y relaciones son testeadas como mecanismo para conocerlas (Gross 2015). Por último, los experimentos comparten la manufacturación o definición de un escenario, o lo que Isabelle Stengers (2000) llama una localidad: los experimentos son aparatos o espacios sociomateriales para estudiar las propiedades de un objeto o fenómeno a través del (relativo) control de los elementos que potencialmente definen su comportamiento.

Más allá de las características de los experimentos, las etnografías en laboratorio (Latour y Woolgar 1979; Knorr-Cetina 1981) fueron precisamente mostrando los complejos procesos epistémicos y ontoló- 
gicos involucrados en la configuración de la localidad experimental. Primero, el experimento es ante todo un ejercicio de demostración: como una coreografía o puesta en escena, el experimento con toda su arquitectura material siempre se realiza en función de un público que debe ser convencido o al menos seducido (Shapin y Schaffer 1989). En segundo lugar, el montaje experimental (el conjunto de elementos materiales, infraestructurales y tecnológicos involucrados en la realización de un experimento) no es solo un medio a través del cual se despliega un experimento, sino que define cómo, dónde y qué hace un experimento. Es decir, el experimento no es externo al fenómeno que estudia, sino que ayuda a crearlo.

$Y$ este es precisamente el tercer elemento clave para entender la función de los experimentos en la sociedad contemporánea: que no estudian objetos o fenómenos que le preexisten, sino que los hacen existir en el mismo proceso experimental (Muniesa y Callon 2007). Puesto de otra manera, el experimento genera o provoca la existencia de las cosas sobre las que interviene. En tanto localidad, crea condiciones que de otra manera no se encontrarían en la naturaleza, lo que sucede en el experimento solo existe en y por él. Un caso clásico son las bacterias de Pasteur (Latour 1988). Desde una perspectiva positiva las bacterias existen en el mundo independientemente de cualquier intento del ser humano por conocerlas. Pero como lo pone Bruno Latour (Ibíd.), desde una perspectiva pragmatista fue solo con el laboratorio de Pasteur y sus experimentos cuando las bacterias se volvieron entidades concretas, susceptibles de intervenir y con capacidad de acción. Esa bacteria, la bacteria "social", con sus capacidades, características y aplicaciones, no existía con anterioridad a los experimentos de Pasteur sino que fue hecha existir en estos: fue necesario un experimento para generarlas y hacerlas aparecer en la vida social.

Lejos de ser solo mecanismos de generación de conocimiento, los experimentos, por tanto, tienen capacidades ontológicas: crean las entidades sobre las que intervienen. Lo importante para nuestro argumento es que esta figura del experimento ha sido usada para entender procesos de participación ciudadana. Los procesos de participación -desde las conferencias de consenso hasta las mesas de discusión- pueden ser vistas como montajes sociomateriales especialmente diseñados para provocar un tipo particular de implicación y comunicación (Lezaun 2007; Lezaun y Soneryd 2007). Salas, micrófonos, sillas, selección de participantes, diseño de actividades, post-it, lápices, coffee breaks y una plétora de metodologías de interacción, teorías de la comunicación y expertos en comunidad (Rose 1999) son articulados para generar un espacio donde los participantes puedan, no solo dar su opinión, sino también constituirla como tal e involucrarse en el problema en cuestión. En otras palabras, los ejerci- cios de participación pueden ser vistos como arenas donde no solo participan ciudadanos, sino también donde estos se crean: el sujeto participante, con su voluntad y capacidad de involucramiento, no preexiste al ejercicio, sino que es performado como tal en la maquinaria participativa.

En estos experimentos en participación, las teorías que informan las metodologías utilizadas son clave para modular al "ciudadano" participante (Lezaun y Soneryd 2007). Ideas sobre racionalidad comunicativa, empoderamiento, democracia participativa y acción colectiva son modeladas y materializadas en artefactos metodológicos que van definiendo qué es un buen y mal participante, cómo se validan opiniones constructivas (y cuales son desechadas por parciales o ideológicas) y cuál es la meta esperada del ejercicio. Al mismo tiempo, distintos escenarios experimentales y metodológicos definen distintos públicos. Metodologías fundadas en encuestas tienden a enactar a ciudadanos más "informados" mientras que aparatos experimentales que descansan en métodos dialógicos y conversacionales performan sujetos más "emocionales" (Braun y Schultz 2009). En definitiva, a través del aparato metodológico, de las teorías que dibujan los resultados esperados y la gestión situada del proceso, los experimentos en participación no se limitan a hacer participar a los ciudadanos, sino que los moldean como tales, perfilando sus subjetividades, capacidades e intenciones.

Mientras la invención ontológica de los experimentos en participación está bien documentada, menos se han estudiado los conflictos entre el sujeto imaginado por el experimento y el que se encuentra por fuera de este. Los experimentos, en efecto, no siempre discurren desproblematizadamente (Michael 2009; Felt y Fochler 2010). Muchas veces las expectativas experimentales sobre el ciudadano óptimo o ideal, movilizadas en las teorías y metodologías de la maquinaria experimental, chocan con múltiples resistencias y obstinaciones. Por ejemplo, Tironi (2014) investigó un experimento participativo en el contexto de reconstrucción después del terremoto y tsunami del 2010 en Chile, mostrando hasta qué punto el aparato se sustentaba en ideas, a su vez nutridas por teorías sociales, sobre lo que significa la "participación" óptima y altruista que no ajustaban con las condiciones e imaginarios de quienes supuestamente tenían que dejarse performar como participantes, ni con las múltiples precariedades y ansiedades que envolvían al ejercicio completo. Lo relevante de la investigación de Tironi (íbíd.) es que muestra que el choque no se redujo a producir resultados distintos a los esperados por los experimentadores, sino que desestabilizó la capacidad generativa del experimento completo: el experimento dependía de la coincidencia ontológica entre el participante imaginado por el aparato experimental y requerido para su correcto despliegue, por un lado, y el afectado por el desastre 
con sus necesidades y angustias que debía participar en el experimento, por el otro. Esa coincidencia no se produjo, y el experimento, al no encontrar la ductilidad ontológica del participante para aceptar las propuestas éticas, prácticas y políticas del ensamblaje experimental, fracasó.

Nos interesa particularmente resaltar las condiciones y potencialidades de este fracaso experimental. En la literatura sobre participación en general, y en contextos de proyectos energéticos en particular, es usual explicar los problemas encontrados por los ejercicios de implicación como fallas metodológicas (Newbold and Foulkes, 2004). Sin embargo, este tipo de explicaciones no atienden al intento de generación ontológica puesto en marcha en los experimentos. La realidad se hace en diversos espacios y prácticas (Mol 2002), por tanto las realidades enactadas en los experimentos pueden encontrarse, a veces conflictivamente, con realidades cristalizadas en otros espacios y prácticas. En su reflexión sobre la comparación etnográfica, el antropólogo Eduardo Viveiros de Castro (2004) acude a una anécdota contada por Lévi-Strauss sobre un evento ocurrido en las Antillas durante la conquista (ver también Latour 2004). Cuenta la anécdota que, mientras la gran pregunta para los conquistadores españoles era, en el contexto de la Inquisición, si los indígenas tenían alma y por tanto si podían ser tomados como potenciales hijos de Dios, los indígenas se hacían una pregunta simétricamente inversa; a saber, si los españoles tenían cuerpo, en el entendido de que para los nativos la fuerza espiritual era evidente, no así la forma que esta podía adoptar. De este modo, mientras los españoles realizaban experimentos deliberativos en Valladolid para determinar la condición espiritual de los indígenas, estos desplegaban sus propios experimentos, ahogando a los españoles para ver si sus cadáveres flotaban y por tanto confirmar su consistencia corporal. Viveiros de Castro resalta lo que denomina "equivocación" en este particular juego simétrico de comparaciones: el hecho de que lo que hace el experimento de los españoles y el de los nativos no es intervenir sobre el mismo objeto enunciado de forma distinta -0 , si se prefiere, tener distintas perspectivas culturales ante la misma naturaleza- sino interactuar y constituir naturalezas diferentes.

Llevado al plano de los experimentos en participación, se podría decir que la equivocación de Viveiros de Castro involucra lo que en este artículo llamamos disenso ontológico: el choque, muchas veces violento y sin solución de continuidad, entre distintas ontologías. Dicho de otra manera, el fracaso de los experimentos en participación puede leerse como un conflicto que no se juega en metodologías deficitarias incapaces de ajustar distintas perspectivas sobre un mismo objeto, sino en la colisión de formas múltiples, muchas veces inconmensurables, de pensar, habitar y practicar mundos (Tsing 2011; Puig de la Bellacasa 2011; Haraway 2016). La recalcitrancia que enfrentan los experimentos participativos estriba en que figuras como democracia, participación, igualdad y desarrollo -o agua, energía, tierra y bosque- lejos de ser entidades neutras y universales, se entrelazan afectiva y vitalmente de maneras irreconciliables entre los distintos actores en pugna (De la Cadena 2015; Chapman 2013). Siguiendo la idea de "desórdenes ontológicos" elaborado por Bonelli (2012), se podría decir que estos disensos ontológicos en el marco de experimentos en participación emergen "cuando enfrentados a problemas iguales o similares, los diferentes actores encuentran diferentes formas prácticas de reforzar sus propias definiciones de sociedad" (Ibíd., p. 4).

El resultado es que ni la noción de "participación" ni de cualquiera de los seres, fuerzas y entidades que pueblan e incentivan los experimentos participativos en el contexto de conflictos energéticos es singular $u$ objetiva (Howe y Boyer 2015). Por el contrario, al cuajar y existir en el plano de la vida, desafían cualquier posibilidad de llegar a un acuerdo racional-liberal (Tironi 2016). Así, la figura del disenso es movilizada en este artículo más como un espacio generativo de nuevas posibilidades que como la simple imposibilidad de llegar a un consenso. Siguiendo a Rancière (1996), tomamos los momentos de disenso ontológico -situaciones donde distintos mundos chocan en el contexto de experimentos en participación- como oberturas en las que emerge la posibilidad de reparticionar lo sensible: situaciones de incertidumbre en los que la realidad no puede ser fijada, y por tanto donde nace la posibilidad de invocar otras formas ontológicas. El poder de la otredad en el concepto del disenso ontológico es por tanto fundamental. La colisión de distintas ontologías en el despliegue de experimentos participativos permite que lo otro -modos de existencia alternativos- esté siempre presente como un trasfondo político, y por tanto como un imperativo ético: toda manifestación y movilización ético-política debe realizarse asumiendo que la actualidad de lo que es (una identidad, un valor, un ideal) está siempre en lo que puede llegar a ser, o sea una potencialidad que obliga a los involucrados a mantener abierta la posibilidad de transformación (Derrida 1993). Para Povinelli (2011), es en este espacio entre lo que se es y lo que se puede llegar a ser donde se juega la posibilidad de perseverancia ética y, por tanto, donde se articula la existencia política de proyectos sociales alternativos en la sociedad neoliberal. Es decir, los disensos ontológicos en el contexto de experimentos participativos -el choque entre modos de existencia inconmensurables-crean una indeterminación que permite mantener abierta la posibilidad de otros mundos, otras naturalezas y otros proyectos sociales. Los disensos ontológicos son, puesto de otro modo, en sí mismos generativos, y esta vitalidad debe tenerse en consideración a la hora de evaluar la capacidad inventiva de los experimentos. 
Para resumir, la capacidad generativa de los experimentos no se aloja solamente en el despliegue (exitoso) de su maquinaria sociomaterial, sino también en los momentos de fractura e indeterminación en que las ontologías imaginadas y propuestas por el experimento se estrellan contra otras realidades, mundos y seres. Esta perspectiva puede ser, apostamos, especialmente relevante para estudiar el caso de Chanquín-Palihue. EI PAEI no es el primer intento por incluir a comunidades indígenas, y más ampliamente a la ciudadanía no experta, en proyectos de gran envergadura. De hecho, el PAEI puede ubicarse dentro del giro participativo que han seguido las políticas públicas en general (Jasanoff 2004) y los proyectos energéticos en particular (Devine-Wright 2014). Sin embargo, en tanto experimento, el PAEI puso de manifiesto que el desafío de la participación ciudadana no está tanto en el ajuste de sus metodologías sino en los disensos ontológicos que produce.

\section{INFRAESTRUCTURAS EÓLICAS, HUILLICHE MÚLTIPLE}

\footnotetext{
"¿Qué buscamos? Un nuevo enfoque de inversión, que capitalice a las comunidades y que valorice sus recursos, de manera que puedan aportar al capital de las empresas que se crean y que al cabo de un plazo permita que la empresa sea propiedad mayoritariamente indígena".
}

Presidenta Michelle Bachelet en inauguración del PAEI, 26 de junio del 2016.

EI PAEl busca integrar al mundo indígena en la economía de mercado. $Y$ lo hace incentivando la creación de empresas indígenas. Se trata, tal como lo resaltó la propia presidenta de la república, de un "nuevo enfoque de inversión". El objetivo final del PAEI, y la ruta política que propone el BID, es la participación en el mundo empresarial como vehículo para la integración social. En efecto, según el BID uno de los principales escollos para la integración que han enfrentado los pueblos originarios en Chile es precisamente su pobre inserción económica. "En el país", dice el BID (BID 2016: 2), "la población indígena tiene un muy bajo acceso al financiamiento bancario", y esta situación no solo mantendría a los pueblos originarios fuera de los mercados de mayor valor sino también de la posibilidad de incorporarse de manera más significativa a la vida pública del país. El problema para el BID no sería el acceso a pequeños créditos o subsidios, a los cuales los pueblos originarios ya poseen acceso. El problema estaría en que estos instrumentos fueron "diseñados para atender las necesidades de emprendimientos de muy baja escala, y no resultan apropiados para los negocios indígenas orientados al crecimiento" (BID 2016: 3, énfasis añadido).

EI PAEl está orientado, por tanto, a la creación de un nuevo tipo de subjetividad económica en el pueblo indígena. Esa es la apuesta del experimento: crear las condiciones que le permitan al indígena saltar del pequeño emprendimiento a la empresa; pasar del proyecto de bajo valor y de escala artesanal-familiar a iniciativas de alto retorno económico y con "el potencial de generar externalidades hacia sectores clave del país y contribuir a mejorar su clima de convivencia pluricultural". En palabras del BID, crear las condiciones para que los indígenas puedan "convertirse en empresarios del sector eléctrico de Chile" (Ibíd., p. 52, énfasis añadido). Los obstáculos son varios y profundos ${ }^{3}$, pero el BID es optimista: el "indígena empresario" existe en potencia, solo se requiere llenar lagunas epistémicas, reforzar habilidades estratégicas y satisfacer necesidades institucionales para que este se vuelva una realidad. Y esa es precisamente la meta experimental del PAEI: provocar la emergencia de un nuevo emprendedor indígena entregando los instrumentos necesarios (financieros, informacionales, culturales) para que el mundo indígena logre vincularse al mercado y al desarrollo. Y el proyecto Chanquín-Palihue sería la puesta en escena y el medium para esta incubación: un experimento donde lo que se testea no es solo el desarrollo de un tipo de tecnología energética sino, sobre todo, de un tipo de identidad.

Pero la provocación de ese "empresario indígena" probó ser más compleja de lo esperado. Como en todo experimento, el de Chanquín-Palihue requería de la colaboración del objeto experimental para ser modelado según los parámetros de la intervención: todo experimento depende de la voluntad material y epistémica del objeto para aceptar su transformación, o al menos para dejarse ser intervenido (Rheinberger 1997; Hinchliffe 2007). En Chiloé el experimento dependía de la posibilidad de encontrar las condiciones eólicas e infraestructurales necesarias, pero también -y sobre todo- de encontrar a un indígena con las disposiciones para convertirse en empresario. Y esta búsqueda no fue sencilla.

Lejos de validar sin fricciones a los protagonistas del experimento, este tuvo que lidiar con un huilliche que desconfiaba tanto de Cuyul como del propio BID -una situación que no estaba prevista en el guion inicial-. Este choque quedó en evidencia en el mismo encuentro entre el BID y la comunidad Chanquín-Palihue. Una vez terminada la rogativa, Cuyul y Víctor Luna, presidente de la comunidad de Chanquín-Palihue, compartieron sus expectativas y anhelos con respecto al parque eólico, al que describieron como un verdadero "sueño" para la comunidad. La presentación también incluyó una explicación de todos los esfuerzos realizados hasta ese momento y las grandes dificultades encontradas. Se nombraron varias, pero rápidamente quedó claro que el problema más acuciante provenía de quiebres dentro de la misma comunidad. Más específicamente, la eventualidad de un negocio que generaría fuertes sumas de dine- 
ro creó todo tipo de sospechas. No eran pocos dentro de la comunidad, contaron Cuyul y Luna, los que habían cuestionado a estos dos líderes. Se habían esparcido rumores que los involucraban en transacciones económicas sospechosas. A tal punto llegaron las suspicacias que el BID consideró importante dejar por escrito durante el encuentro que "los líderes de la comunidad que han participado en el proceso, realizaron un gran esfuerzo sin recibir ningún tipo de pago por su servicio" (BID 2016: 14). La sospecha no era infundada. Era el temor, fruto de una larga historia de engaños y aprovechamientos, a líderes indígenas que en nombre de proyectos de desarrollo usurparon tierras o hicieron arreglos por debajo de la mesa. Era la memoria de corrupciones solapadas y "buenos negocios" que terminan, siempre, con las familias mapuche más pobres de lo que estaban.

Y era el temor, más profundo y ontológico, al dinero como fuente de corrupción. La figura integracionista o no tradicional (Blaser 2016) de Cuyul puede haber motivado parte de estos temores. Pero en comunidades que han sido sistemáticamente estafadas y que han visto cómo la economía monetaria muchas veces ha traído más problemas que beneficios, la abundancia de dinero, sobre todo cuando viene bajo la forma de promesas externas, es vista como dañina: la acumulación capitalista es sentida como una malignidad que termina corrompiéndolo todo. Así lo dijeron abiertamente los propios representantes de Lanco en el encuentro. "Cuando hay plata", sentenciaron con preocupación, "las comunidades ya no saben qué hacer, quedan más pobres que los pobres". Cuyul, líder material y moral del proyecto, tenía que enfrentar este fantasma: además de la continua sospecha de que algo opaco escondían los líderes del experimento, era en sí mismo dudoso que la llegada de grandes cantidades de dinero a la comunidad fuese necesariamente positivo. Más bien, por el contrario, detrás de la promesa económica del proyecto se agazapaban el alcoholismo, los quiebres familiares y desmembramiento comunitario, tal como ha sucedido tantas veces en proyectos similares.

Este temor se complementaba con otro objeto de rechazo: la desconfianza generalizada a la figura de la "empresa". Al menos dos siglos de ventas forzadas, proyectos ilegales y promesas incumplidas han hecho que la comunidad huilliche de Chiloé vea con profunda sospecha las operaciones de empresas de cualquier tipo (estatales o privadas, chilenas o internacionales). Cargada por un proyecto nacional y extractivista que ha sido usualmente violento, la "empresa" es una figura cifrada en el miedo y la suspicacia. No fue de extrañar, por lo mismo, que Cuyul y Luna insistieran en que el desafío fundamental estaba en cómo se administrarían los recursos y cuál sería la empresa asociada para la construcción del parque. El proyecto dependía de la posibilidad de conformar una sociedad para ges- tionar una iniciativa económica de esta magnitud. Quién conformaría esta sociedad, cómo se constituiría y de qué forma participaría la comunidad eran temas cubiertos por una espesa sensación de duda y recelo, sin contar con la ya densa nube de desconocimiento, incredulidad y desánimo que envuelve la nomenclatura tecno-legal.

Efectivamente, y a pesar de los esfuerzos para hacer inteligibles las explicaciones técnicas, el proyecto estaba cruzado por una gramática experta que la comunidad no lograba entender del todo. Aún más, el proyecto seguía procedimientos estandarizados y que parecen evidentes para proyectos de este tipo, pero que no coincidían con las condiciones de verosimilitud y legitimidad esperadas por la comunidad. Por ejemplo, en virtud de la necesidad de asegurar la existencia de viento a lo largo de todo el año, condición técnica mínima para el desarrollo del proyecto, el BID realizó una serie de pruebas eólicas en la zona. Para no crear falsas expectativas, el BID optó por no informar a las comunidades circundantes de las prospecciones que se realizaban en Chanquín-Palihue, "ya que el resultado negativo en la medición del viento haría fracasar el proyecto" (PAEI-BID 2016: 9). Dado que se trataba únicamente de exploraciones de factibilidad preliminares, solo se informó a las familias en cuyos predios se habían emplazado las antenas para las mediciones. Los estudios establecieron una capacidad potencial de generación de 50MW (Ibíd., p. 16), lo que hacía factible el proyecto 4 .

Sin embargo, los rumores comenzaron a extenderse. Aunque se insistió en que se trataba solo de estudios prospectivos y que, por tanto, no sólo era necesario sino que era deseable no informar a todas las comunidades (para evitar la frustración de expectativas), las comunidades no lo vieron de esa manera. La probidad técnica y social para unos era secretismo y malas prácticas para otros. EI BID asumió, sin cuestionamientos, que las comunidades entenderían la racionalidad técnica, e incluso ética, de su decisión de no informar. Y no fue así. Es más, hasta pocos días antes del encuentro del 21 de enero las familias de comunidades circundantes no sabían de las prospecciones ni se les había extendido una invitación a participar del evento donde el proyecto se debatiría. La acalorada discusión a la entrada del fogón entre los organizadores y miembros de comunidades vecinas que no fueron informadas muestra hasta qué punto el experimento no calibró la pretensión de universalidad de sus parámetros.

Otro espacio de conflicto entre el sujeto imaginado y esperado por el experimento y lo que se encontró en terreno fue la forma que adoptan los beneficios económicos en proyectos energéticos comunitarios y el modo en que se asigna "valor" a paisajes, espacios y objetos. En efecto, uno de los desafíos técnicos del proyecto era la necesidad de evacuar la electricidad 
generada en el parque eólico para inyectarla al sistema interconectado. Esto requería, por de pronto, la negociación de una propuesta conjunta entre las 17 comunidades de Huillinco-Cucao ${ }^{5}$. No era una operación fácil, sobre todo porque el BID propuso que cada una de las 17 comunidades se beneficiasen en partes iguales del proyecto. "La PROPUESTA", señala el BID, "tiene como propósito crear una empresa que represente los intereses de las comunidades involucradas y que también sea la titular del desarrollo del proyecto ante la autoridad competente. Si lo aprueban las comunidades, la empresa que tendrá un nombre escogido por todos ${ }^{6}$ tendrá una estructura de capital con una participación para cada una de las 17 comunidades de Huillinco-Cucao del 5,88 \%" (BID 2016: 21).

Sin embargo, la participación porcentual de SEICH dependía de la valorización de su participación y de la financiación que necesariamente tendría que gestionar, un esquema que se asumió como evidente. Al menos para el BID era indiscutible que la sociedad debía asociarse con inversionistas privados para crear la empresa de generación de energía. Esta empresa se constituiría con una nueva estructura de capital en donde la SEICH sería dueña de una parte de este capital y el inversionista privado del restante. El aporte de las comunidades serían los costes de los estudios, cubiertos por el BID, y la renta de sus tierras $^{7}$. Las estimaciones del PAEI-BID era que el aporte de la SEICH a la inversión total no superaría el $8 \%$. Con un préstamo de instituciones del estado el aporte patrimonial de la SEICH a la empresa de generación podría incrementarse al $20 \%$.

La propiedad económica de las comunidades huilliche sería, entonces, mucho más tímida de lo que promocionaba el experimento. $Y$ un incremento en esta dependía de acceder a créditos que el mismo PAEI-BID reconocía como inalcanzables para comunidades incapaces de dar las garantías requeridas por el sistema financiero. Gestionar una ayuda económica con organismos públicos era una alternativa que muchos vecinos, resistentes a entablar relaciones con el Estado chileno, no estaban dispuestos a ejecutar.

Adicionalmente, y bajo el supuesto de que se lograse encontrar aportes estatales o privados para constituir la empresa, las previsiones indicaban que la generación y comercialización de energía solo comenzaría 4 o 5 años después de la puesta en marcha del proyecto. Esto implicaba que las ganancias solo serían visibles en un plazo de 10 años. Y las "ganancias" tenían una forma muy particular. Las utilidades económicas del experimento no quedarían a libre disposición de las comunidades, sino que tendrían que ser invertidas "en proyectos de desarrollo social". Las utilidades tampoco se traducirían, tal como creían los lugareños, en una reducción "del valor de la energía consumida por las familias de las comu- nidades de Huillinco-Cucao" (BID 2016: 35). Dado el actual sistema eléctrico en Chile, no existe la posibilidad de crear formatos solidarios de facturación para comunidades en territorios generadores. Es decir, mientras todas las expectativas de las comunidades estaban en lograr a través del proyecto una estabilidad económica para sus precarias vidas o, al menos, acceder de forma gratuita a la electricidad que se produciría en sus territorios, el experimento no les entregaría dinero ni electricidad gratis sino recursos para ser invertidos en proyectos sociales tan lejanos como innecesarios para las empobrecidas familias. Estos recursos, además, no solo serían mucho más escuálidos de lo esperado por aquellos que tendrían, a cambio, que permitir la intervención en sus tierras ancestrales, sino que además no se materializarían hasta dentro de una década.

En definitiva, el experimento estructuró sus procedimientos imaginándose a un huilliche emprendedor y moderno, cognitiva y afectivamente dispuesto a la transformación ontológica propuesta por el BID: un huilliche que participaría fluidamente de los procedimientos que el experimento desplegaría para convertirlo en un indígena empresario. Sería un huilliche que confiaría en sus líderes, en el BID y en los objetivos del proyecto; que entendería las condiciones y limitaciones técnicas del proyecto y que, atendiendo a la naturaleza altruista y comunitaria del nuevo capitalismo indígena que se quería promover, no tendría inconvenientes con renunciar a las utilidades directas y a corto plazo.

Lo que queremos resaltar es que el BID no solo se encontró con múltiples formas de ser huilliche, sino que además ninguna de estas formas encajaba con el tipo de "huilliche" que el experimento requería. El proyecto estaba animado por un programa propedéutico específico, a saber, ayudar a constituir un indígena empresario que pudiera implicarse activamente en la economía de mercado. Pero lo que había en la isla era algo muy diferente.

\section{Promesas ontológicas: POtencialidad Ética en Chiló́}

Para mediados del 2016 el proyecto eólico de Chanquín-Palihue se había cancelado. Después del encuentro de enero el BID comienza paulatinamente a desvincularse del proyecto, dejando su conducción en manos de la Corporación de Fomento de la Producción (CORFO) ${ }^{8}$. Esto se debe, en parte, a los problemas encontrados en terreno; en parte, también, por el retiro laboral de Carlos Perafán, quien fuera el impulsor del PAE dentro del BID y el interlocutor directo con Sergio Cuyul y el presidente de la comunidad de Chanquin-Palihue. Para esta, la salida del BID y la consiguiente entrada de CORFO significaba una alianza con el Estado chileno que no estaban dispuestos a formar. 
Sergio Cuyul, articulador clave de la iniciativa, perdía cuatro años invertidos en el proyecto. Pero sin resignarse. Después de la disolución del proyecto, Cuyul empieza a reciclar conexiones y establecer nuevas conversaciones para evaluar la factibilidad de un proyecto similar pero de menor tamaño en la zona de Quilipulli, en la comuna de Chonchi. Este nuevo proyecto se realizaría en alianza abierta con CORFO, entidad que haría de intermediario con diversos organismos estatales y asociaciones internacionales (BID, GIZ, etc.).

El fracaso del experimento en integración de Chanquín-Palihue y particularmente la figura de Sergio Cuyul permiten revisar hasta qué punto el proyecto permitió imaginar otras formas de ser huilliche. Más allá de la evaluación normativa del proyecto modernizador de Cuyul, nos interesa explorar cómo su irrupción permitió plantearse una pregunta ética fundamental: quién y cómo se define lo huilliche, y de qué maneras lo huilliche siempre está en exceso a lo que el término puede definir. Esta posibilidad de exceso más allá de lo actual es crucial para entender la potencialidad ético-política del experimento de Chanquín-Palihue.

Aunque desde otro contexto y en la perspectiva de otros problemas, la filosofía de Jacques Derrida ha sido clave para pensar esta pregunta ético-política. Para Derrida vivimos en un mundo de fuerzas y relaciones que no dependen de nuestra voluntad y hacer. Somos y vivimos entre y desde fuerzas que siempre pueden llegar a ser algo diferente. Nuestra existencia se presenta, como lo dice Derrida, promisoriamente, en la clave de la promesa, o sea como algo que es y se enuncia en el momento actual, pero que tendrá que devenir en y con condiciones cambiantes y obstáculos vitales. Y ahí emerge, según Derrida, la posibilidad de la ética, que es siempre una promesa: la ética nace solamente cuando se hace referencia a un futuro que no se conoce y que estará siempre abierto a la diferencia9 ${ }^{9}$. Es por esta razón que para Derrida la potencia ética de conceptos como el de justicia o democracia -y nosotros podríamos añadir el de lo huilliche- no pueden leerse en lo que son o pueden hacer ahora, sino en su posibilidad de futuras revisiones y experiencias: nadie puede cerrar lo que la idea de justicia y sus posibilidades pueden ofrecer y en lo que se pueden convertir. La ética es por tanto un espacio inventivo que permite la multiplicación de las posibilidades, no su restricción -o como lo pone Colebrook (2016: 103), en la ética derrideana "la única imposibilidad es la determinación de antemano que ciertos eventos serían imposibles"-. La fuerza y la condición ética de prácticas o enunciaciones descansa en su poder generativo más allá de cualquier situación ya formada.

Desde esta perspectiva derrideana se vuelve crucial entender cómo el experimento en integración de Chanquín-Palihue en particular, y de la experimen- talidad en general, logran expandir posibilidades ontológicas. El experimento fracasó puesto que la integración esperada requería producir a un huilliche moderno y altruista que nunca cuajó del todo. Pero el experimento tuvo la capacidad, aunque haya sido un efímero momento de fractura, de problematizar promisoriamente lo que significa lo huilliche, y por tanto para invocar una indeterminación ontológica que, siguiendo a Derrida, tiene poderosas implicaciones políticas. Esta indeterminación aparece cuando el BID supuso valores y principios universales que, sin embargo, chocaron frontalmente con los modos de hacer y pensar de las comunidades involucradas. También cuando estas participan en ceremonias ancestrales que no conocían y en un idioma, el mapudungun, que no dominaban. Y Sergio Cuyul, en sí mismo y en las prácticas y proyectos que ha buscado e impulsado en las últimas dos décadas también pueden leerse, proponemos, como una particular forma de promesa ontológica.

Sergio Cuyul, como otros niños indígenas de su generación, migró de Chiloé y regresaría 30 años después. Completó su educación básica en la región de Aysén, donde su madre migraría al ser despojada de la tierra en la que vivían en Chiloé. Luego de la escuela-hogar, programa de inclusión creado durante el gobierno de Allende para aquellos niños que vivían lejos de los establecimientos educacionales, es enviado a Temuco para completar la educación secundaria, hasta ingresar en la Universidad de la Frontera, donde finalmente se recibiría de trabajador social.

El fin de la dictadura trajo el reforzamiento de programas de desarrollo local y el nacimiento de un "giro indigenista' en las políticas públicas, consolidado en la fundación en 1993 de la Corporación Nacional de Desarrollo Indígena (CONADI), organización gubernamental enfocada a "Promover, coordinar y ejecutar la acción del Estado en favor del desarrollo integral de las personas y comunidades indígenas, especialmente en lo económico, social y cultural" (CONADI 2008). Como en otras partes de América Latina, la aparición a mediados de los '90 de la CONADI - y más ampliamente de todo el aparataje institucional compuesto por oficinas indígenas municipales, ONG, agencias internacionales y programas - estatales transformó profundamente el modo de ser indígena en Chile. Por un lado, la intervención masiva para la gestión del "asunto indígena" ayudó a desacelerar la reivindicación autonomista, reforzando el modo de dominación colonial clásico del Estado nación en Chile (Campos 2002). Como lo ponía el dirigente mapuche Hilario Hurilef a comienzos de los 2000 , "la democracia nos descabezó la organización pagándoles sueldo a los dirigentes y llevándolos a su lado" (Ibíd., p. 43). Al mismo tiempo, sin embargo, la nueva institucionalidad indígena significó el acceso a recursos políticos, sociales y económicos exclusivos para el mundo indígena, y el nacimiento de una pla- 
taforma política para su relación con el Estado y el debate sobre su autonomía cultural y territorial que no existía (Campos 2002; Vergara et al. 2005). La CONADI y el ensamblaje institucional que trae consigo ayuda a constituir un nuevo espacio político para la construcción identitaria en el mundo indígena, una identidad que ya no oponía pueblos originarios al Estado nación sino que buscaba la mutua colaboración.

Cuyul regresa a Chiloé y pasa a formar parte de una nueva generación de dirigentes indígenas, con estudios universitarios y capacidades expertas, que ve en el Estado a un socio al cual pragmáticamente vincularse. Junto con este impulso y en vistas de los nuevos programas estatales de desarrollo ruralindígena que el gobierno empezaba a multiplicar, Cuyul funda en 1997 la Federación de Comunidades Huilliches de Chiloé (FCHCh) como plataforma para postular y administrar proyectos de gestión local.

A diferencia de otras organizaciones indígenas en la isla, por ejemplo del Consejo General de Caciques de Chiloé, la FCHCh estaba menos apegada a estructuras de organización indígena tradicional ${ }^{10}$. Y si bien la FCHCh mantenía una relación de desconfianza con el Estado chileno, también buscaba aprovechar las posibilidades que abrían los programas estatales de desarrollo y educación indígena. La figura de Cuyul y la de su imaginario en torno al huilliche emprendedor, por tanto, no cuadraban ni con los modos de organización apegados a ritos y autoridades ancestrales, ni con los modelos de gestión "modernos" del Gobierno chileno y otras agencias de desarrollo. Desde sus comienzos la FCHCh tuvo que enfrentar a la resistencia del "cacicado" como organización tradicional de Chiloé por un lado, y a la necesidad constante de diferenciarse de la CONADI por el otro. Los primeros no veían con buenos ojos la irrupción de dirigentes que propusieran otras versiones de lo huilliche y lo indígena en la isla; la segunda se debía mantener a raya, ya que, si bien formalmente no había ninguna oficina de CONADI en Chiloé en aquella época, el distanciamiento de Cuyul con esta se hacía imperioso para no ser confundido como funcionario a sueldo de una institución gubernamental que, en general, levanta más sospechas que simpatías entre las comunidades. Consecuentemente, la FCHCh operó la mayor parte del tiempo sin ningún financiamiento estatal y, en sus comienzos, a duras penas con donaciones y apoyo voluntario de gente de la isla.

La situación de la FCHCh cambia bruscamente el 2000. Ese año, y de forma relativamente fortuita, un donante suizo se acerca a la federación para ofrecerle financiamiento para proyectos de fortalecimiento de las comunidades huilliches de Chiloé con una durabilidad de cinco años. El financiamiento de la FCHCh se multiplicó por diez y generó un vuelco en su capacidad de gestión. Con este apoyo se compra un vehículo con capacidad de traslado de al menos 10 personas, lo que facilitó el acercamiento a comunidades más alejadas, se fortaleció la gestión y solicitud de becas indígenas para los jóvenes y se iniciaron otras líneas de trabajo con éxito. Por ejemplo, se inicia un proyecto de titularización de tierras y posteriormente de los derechos de agua. Este proyecto nace de un taller prospectivo que los afiliados a la FCHCh realizan el año 2004 para definir sus objetivos a largo plazo. Una de las metas consensuadas era la de asegurar los derechos de agua para las comunidades, meta que con la ayuda del financiamiento suizo se alcanza en solo dos años.

A través de la FCHCh Cuyul empieza a darle forma a un modo de ser huilliche que se ubica conflictivamente dentro del espacio político postransicional de la isla. Si bien sus prácticas e imaginarios responden a lo que Escobar ha llamado multiculturalismo neoliberal (2008), Cuyul mantiene su independencia con el Estado y no responde a la figura del etnoburócrata (Boccara y Bolados 2010). Cuyul parece buscar otra forma de pensar lo huilliche en el Chiloé actual. Como una especie particular de objeto de frontera (Star y Griesemer 1989), lo huilliche en la política identitaria de Cuyul conecta al mundo económico globalizado y los espacios legales e institucionales de desarrollo con la cultura ancestral y el territorio, pero también los separa. Durante estos años la FCHCh busca referentes en gestión indígena de frontera (en el sentido de Star y Griesemer) realizada en otros países, como Canadá, Australia y Nueva Zelanda, participando incluso de algunos encuentros internacionales que fueron cubiertos en parte con el financiamiento obtenido de fondos suizos. Por otro lado, mantiene una prudente distancia con los organismos gubernamentales nacionales, al mismo tiempo que realiza acercamientos concretos y efectivos con las instancias públicas competentes según la gestión en cada caso administrativo (becas estudiantiles, titularizaciones, etc.).

El año 2006 el financiamiento se acaba y comienza una dura etapa para la FCHCh. Sin financiamiento, la participación de las comunidades comenzó a decaer, apareciendo problemas y conflictos que terminaron por disolver la Federación. Es en este escenario que, en 2011, aparece el BID de la mano de Raúl Rupailaf y Carlos Perafán con la idea de un parque eólico con participación huilliche. Es importante resaltar que el encuentro entre el BID y Cuyul ocurre cuando Chiloé empieza a constituirse en los discursos, imaginarios y prácticas tanto de la industria como del Estado en el corazón del "poder eólico" (Howe y Boyer 2015) chileno. En el contexto del giro sustentable hacia una matriz energética más limpia y renovable, el gobierno ha prometido una revolución en el ámbito de la generación eléctrica, con la meta de contar con una matriz compuesta en un $50 \%$ por energía renovable para el 2050. Las energías renovables no convencionales, como la eólica, cargan con la promesa de un "capita- 
lismo verde" que permitirá desarrollo económico y social sin hipotecar el futuro ambiental del país. Por sus características geográficas, Chiloé fue rápidamente identificado como potencial clúster para una industria de generación eólica. Los proyectos eólicos en la isla no han estado exentos de problemas ${ }^{11}$, pero una visita a Castro, la principal ciudad de Chiloé, evidencia la fuerza con que se ha instalado la promesa eólica en la isla: oficinas técnicas, ONG, seminarios y organizaciones ciudadanas le han dado al tema eólico una particular condición de "proyecto," a medio camino entre oportunidad de econegocio, prospección experimental y emprendimiento extractivista.

Con todo, el proyecto de un parque eólico auguraba, a los ojos de Cuyul, la posibilidad de congregar una vez más a las familias y comunidades huilliches que permanecían dispersas. El encuentro con el BID fue, en este sentido, feliz para ambas partes. Por un lado, el BID reconoce en Cuyul al tipo de indígena moderno que encarnaba los principios de emprendimiento, liderazgo y gestión que el proyecto requería e imaginaba. Por su parte, Cuyul encuentra en el BID la posibilidad de desarrollar un proyecto a gran escala que permitiría mejorar sustantivamente la calidad de vida de los huilliches de la isla, a la vez que empoderarlos mediante una actividad económica de envergadura y respetuosa con la naturaleza. "Efectivamente", nos dijo Cuyul la primera vez que hablamos con él, "estamos desarrollando un proyecto en comunidades indígenas de construcción de un parque eólico mapuche-huilliche cuyos propietarios seremos nosotros los huilliche". La figura del "propietario" huilliche, movilizada con orgullo y expectativa por Cuyul, concentra el espíritu del experimento y del encuentro entre el BID y el dirigente: la posibilidad de crear una nueva subjetividad en la que ancestralidad y economía de mercado se mezclarían, donde ser indígena no fuese a contrapelo de ser empresario, un proyecto en el cual desarrollo y naturaleza fuesen compatibles, donde tierra y propiedad por fin fuesen de la mano.

La figura de Cuyul y la ecología de prácticas que trajo consigo son fundamentales para entender a cabalidad el experimento de Chanquín-Palihue y las capacidades éticas que este abrió. El proyecto no solo se cuaja en su empuje y obstinación, sino que también se cae por los conflictos que generó la búsqueda del huilliche emprendedor que Cuyul encarna y que el experimento necesitaba: el proyecto fue ante todo una indagación experimental sobre la identidad huilliche en la isla, y Sergio Cuyul se ubica al centro de esta exploración. Cabe recordar que la cancelación del proyecto coincide con la movilización de las comunidades huilliche de Chiloé por el reconocimiento de sus territorios ancestrales y de su identidad como grupo indígena diferenciado de los huilliche continentales. A mediados del 2016, al mismo tiempo que el proyecto eólico se desarticula- ba, el Consejo Mayor de Caciques y Comunidades Huilliches de Chiloé pedía una audiencia en la Cámara de Diputados. Este era el mismo grupo que en el encuentro con el BID, pidió conversar con los encargados del programa y se había retirado del fogón en forma temprana. En la Cámara de Diputados el Consejo Mayor solicitó una reforma de la ley indígena para que la comunidad huilliche de Chiloé fuese reconocida como tal. Señalaron con inquietud que la identidad indígena de la isla se estaba instalando a través de símbolos mapuche-continentales que afectaban a la autenticidad cultural de la comunidad huilliche chilota.

En un particular juego de desórdenes ontológicos (Bonelli 2012), mientras Cuyul abandonaba su intento propedéutico y el proyecto eólico se caía por la imposibilidad de fijar qué era exactamente lo huilliche y cómo se componía su identidad, el Consejo Mayor -grupo que había ayudado a develar los múltiples y no siempre conectados modos de ser huilliche en la isla- la celebraba en su excepción y particularidad. El Consejo Mayor y Sergio Cuyul formaron, en este sentido, una particular coreografía política que dejaba al descubierto la alteridad de lo huilliche en Chiloé. La petición del primero ante la Cámara de Diputados tenía por objetivo el reconocimiento identitario, pero en la perspectiva del conflicto con Cuyul exponía, más bien, las dificultades para establecer los contornos de esta. El segundo, en un gesto de invención ontológica paralelo al del Consejo Mayor, intentó fundar una nueva (y moderna) identidad huilliche solo para reconocer su heterogeneidad y obstinación. En el espacio relacional que formaron, los intentos, imaginarios y programas del Consejo Mayor y Cuyul no hicieron más que reforzar lo que el experimento eólico había dejado a la intemperie: que lo huilliche se hace ser de múltiples formas y en distintos espacios, variaciones que coexisten en tensión y continuidad en Chiloé.

Lo que queremos resaltar es la incomodidad ontológica que produjo y ha producido Sergio Cuyul. Esta incomodidad -la sensación que no se está donde se debe estar- se encuentra en la base de la capacidad que tuvo el experimento, a través de Cuyul y su historia, de abrir promisoriamente lo que significa ser huilliche en Chiloé: Cuyul devela que lo huilliche es una subjetividad que existe siempre en potencia y que por tanto deviene en medio, y muchas veces a pesar, de fuerzas, pasiones y prácticas que son tan diversas como incontrolables. Los éxitos y fracasos que enmarcan la política identitaria del experimento muestran que cualquier cartografía dibujada para hacer entendible lo huilliche será siempre excedida, problematizada y extendida por nuevas definiciones.

Y para volver con Derrida, esta indefinición no solo es una constatación sociológica sino también, y sobre todo, una posibilidad ética. No se trata de valorar éticamente la ontología huilliche propuesta 
por Cuyul. Su invocación a un huilliche integrado y moderno encontró, como lo vimos, serios problemas en su propia comunidad, además de ser una ontología resistida desde colectivos indígenas que ven en ella una capitulación política ante el poder estatal-colonial. Sin embargo, y esto es lo que queremos enfatizar, es precisamente el empoderamiento (Stengers 2005) de este debate lo que permite dotar a la pregunta por lo huilliche de potencialidad ética. Si lo huilliche está siempre en exceso a las enunciaciones o prácticas de los actores, esto obliga a asumir que cualquier defensa de lo huilliche debe realizarse en el espacio entre lo que es y lo que podría llegar a ser. Puesto de otra manera, Cuyul nos señala que la reivindicación ética no se aloja en la defensa de una identidad huilliche en particular, sino en la convicción de que lo huilliche está retirado de cualquier intento, tecnocrático o sociológico, estatal o comunitario, por fijar su significado. Cuyul muestra que la fuerza ética de las demandas huilliche en la isla está en el reconocimiento de su poder generativo: en el reconocimiento de que lo huilliche siempre puede ser otra cosa, y que en ese dinamismo inventivo se juega la posibilidad de problematizar los mundos coloniales que han intentado catalogarlo y gestionarlo.

\section{Conclusiones}

El proyecto de un parque eólico con participación huilliche en Chiloé fracasó, pero el intento por articular una nueva identidad huilliche que se integre activamente a la economía chilena sigue en pie. A petición del Gobierno y a la luz de los obstáculos encontrados por el PAEI a lo largo de Chile, a mediados del 2016 el BID aprueba las IFI, o Iniciativas de Fomento Integrales. Se trata de un instrumento financiero para apoyar proyectos indígenas en el marco del PAEI. CORFO y el BID destinarán, en conjunto, un total de 60 millones US\$ para estos efectos. El 12 de diciembre de 2016 se llevó a cabo una reunión en la sede del BID con presencia de una serie de organizaciones sociales preocupadas por el cumplimiento de la iniciativa en referencia a las normas internacionales de derechos indígenas y, en particular, al cumplimiento del Convenio 169 de la OIT y de la Declaración de la ONU sobre los Derechos de los Pueblos Indígenas. La reunión fue convocada después de que el BID recibiera una carta, expresando formalmente su preocupación, del Movimiento por la Defensa y Recuperación de los Territorios, la Red por la Defensa de los Territorios, Región de la Araucanía, y Observatorio Latinoamericano de Conflictos Ambientales (OLCA). A la reunión también asistieron representantes de CORFO, quienes conjuntamente con los representantes del BID explicaron los alcances del IFI, al que describieron como un Fondo de Garantía para que las comunidades pudieran solicitar ayuda financiera a los bancos.
Queda por ver si las comunidades indígenas en general, y la huilliche en particular, aceptarán asociarse con CORFO, a través de las IFI, para acceder a préstamos para sus proyectos. En el caso de Chanquín-Palihue, como se vio, la idea no fue bien recibida. Pero el impulso a proyectos como el de Chanquín-Palihue a través de las IFI muestra hasta qué punto el BID y CORFO seguirán insistiendo en experimentos en integración como el revisado. Esto, consideramos, abre una fértil línea de investigación para la sociología de la experimentación.

En este artículo hemos intentado expandir y enriquecer la discusión sobre la capacidad ontológica de la experimentalidad. Los estudios en ciencia, tecnología y sociedad (CTS) han establecido que la potencia política y epistémica de los experimentos científicos -y del método experimental aplicado a diversas áreas de intervención- está en su capacidad para producir el objeto que interviene. Esto es lo que se ha denominado como la capacidad ontológica de los experimentos: su poder para generar, inventar o crear nuevas entidades o realidades. Los experimentos no operan sobre cosas ya existentes, sino que las hacen existir en el aparato experimental diseñado. El caso del PAEI en Chanquín-Palihue confirma que la participación ciudadana también puede ser leída como un particular tipo de experimento. Este no solo se constituyó como un aparato cuidadosamente articulado para crear condiciones de intervención que no podrían encontrarse de otra manera, sino que también fue una intervención que no tenía precedentes y que por tanto estaba abierta a la incertidumbre: en Chanquín-Palihue la intervención misma fue su testeo. $Y$ tal vez lo más importante para nuestro argumento, lo que vimos en Chiloé fue la articulación de un espacio donde los objetos experimentales, en este caso los propios participantes, se provocaron o hicieron existir en la propia intervención. $\mathrm{O}$ al menos se intentó, porque en terreno las cosas resultaron más complejas de lo esperado. $Y$ es precisamente en este punto donde el caso de Chanquín-Palihue entrega al menos dos elementos para enriquecer el debate sobre las capacidades ontológicas de los experimentos.

Primero, el caso revisado muestra que la invención ontológica tiene límites. Mientras la mejor parte de la literatura CTS sobre experimentos se ha centrado en la capacidad de estos para producir nuevas cosas, entidades o sujetos, poco se han revisado situaciones donde el montaje experimental es problematizado (ver Michael 2009; Tironi 2014 y 2015 para algunas excepciones) y donde el intento generativo choca con objetos recalcitrantes que no se dejan provocar con ductilidad. En Chanquín-Palihue la performatividad de un huilliche moderno asumió como dados presupuestos y principios que fueron cuestionados prácticamente por sujetos que no se ajustaron a lo que se esperaba de ellos. Dicho de otra manera, el caso de Chanquín-Palihue muestra, 
contra la celebración de la experimentación como proceso en la frontera del conocimiento, que los experimentos son aparatos cargados de normatividades y normalizaciones que vuelven reales objetos y entidades en base a guiones ontológicos que son muchas veces problemáticos.

Pero esta problematización del experimento en Chiloé demostró ser altamente productiva, y esta es la segunda conclusión. Lo que muestra el caso de Chanquín-Palihue es que la capacidad ontológica de los experimentos no se juega solamente en su "éxito" $y$, consecuentemente, que su fracaso no puede reducirse únicamente a las violencias ejercidas por los experimentadores contra el objeto de intervención. En efecto, el experimento en integración revisado fracasó por las incongruencias entre el participante deseado y necesario por el experimento por un lado y el huilliche que se encontró en terreno por el otro. Pero también porque lo "huilliche", como figura que invoca un proyecto social (Povinelli, 2011) no pudo, y no podrá nunca, ser reducido a una categoría estática. El experimento fue cancelado por los problemas entre el montaje experimental y el mundo que se resistió a ser intervenido en los términos de este, pero sobre todo porque el experimento reveló la existencia de múltiples formas de ser huilliche que no coincidían: el huilliche ancestral del Consejo Mayor con el huilliche moderno de Cuyul y el huilliche "real" de las propias comunidades conectan solo parcialmente, y todas estas versiones establecen, además, una relación equívoca con lo huilliche continental y más ampliamente con la identidad mapuche en general. El foco en este artículo sobre la figura de Sergio Cuyul buscó precisamente dibujar etnográficamente este juego de conexiones/desconexiones. No se trata de validar políticamente la versión de lo huilliche propuesta por Cuyul -la que como se vio fue desestabilizada-, sino de mostrar su capacidad, a través del experimento eólico, para dislocar la pregunta por lo huilliche.

Aquí reside a nuestro juicio la potencialidad ontológica del experimento: en el poder de lo que hemos llamado disenso ontológico. La incapacidad para llegar a un consenso sobre qué significa ser huilliche en Chiloé -0 el choque entre distintas formas de ejecutar lo huilliche en la isla- permiten crear un espacio de indeterminación donde lo huilliche es más el resultado de un devenir promisorio (Derrida 1993) o de una búsqueda cosmopolítica (Stengers 2005) que estará siempre haciéndose de un acuerdo político ejecutado en la clave administrativa de la regulación o la sanción estatal-corporativa. La producción ontológica del experimento, dicho de otra manera, no está en la constitución de un tipo particular de huilliche, sino en la articulación de una incertidumbre ontológica sobre quién y qué es lo huilliche, es decir, para dejar abierta la pregunta de lo huilliche. Como hemos tratado de insistir, esta apertura permite que proyectos sociales de esta naturaleza adquieran potencia ético-política en el Chile neoliberal: lo huilliche, parece mostrarnos el caso de ChanquínPalihue, puede ser siempre otra cosa, y por tanto puede intentar perseverar como un proyecto que invoca imaginaciones, potencialidades y acciones más allá de cualquier definición sobre lo que puede hacer y ser hoy. A través de su indeterminación ontológica, puesto de otro modo, lo huilliche puede perseverar como un proyecto de provocación de mundos alternativos, tal vez el gesto político fundamental en tiempos actuales.

Para finalizar, es fundamental ubicar estas conclusiones en el marco de la política energética chilena. Proyectos como el revisado responden no solo al esfuerzo por integrar a los pueblos originarios a la sociedad chilena, sino también para "limpiar" la matriz energética de esta. En efecto, las ERNC se multiplican en Chile. El Estado ha colocado esfuerzos y recursos en multiplicar energías renovables y, en general, en dar giro sustentable a la matriz energética. Los proyectos eólicos seguirán apareciendo, y en la medida en que la capacidad de colectivos y comunidades para oponerse a estos proyectos crezca, estos se articularan crecientemente como experimentos en integración como el aquí revisado. Es decir, el gran experimento de la transición hacia energía renovables (Gross 2015) incluirá, necesariamente, modelos experimentales que intentarán incluir a la ciudadanía en proyectos inciertos sobre los cuales no se tienen precedentes. La pregunta crítica es qué se podrá esperar de estos experimentos en integración de cara a la expansión de proyectos renovables en el país. Y lo que nos muestra Chanquín-Palihue es que se necesitarán más que metodologías experimentales para incluir cuidadosamente a los involucrados. Estas metodologías, hemos visto, pueden terminar configurando una inclusión universalista que no ayudará al desarrollo de los proyectos. La experimentación hacia energías más limpias y renovables requiere de experimentos en integración que estén realmente abiertos a lo desconocido y que abran los ensayos no solo a lo que el aparato experimental, diseñado tecnocráticamente, entienda por aquello que debe ser intervenido. Es solo si se permite, por decirlo así, que se experimentalicen los experimentos en integración, haciendo que los objetos experimentales sean definidos en el mismo proceso, es que la participación ciudadana en el gran experimento hacia una transición sustentable puede tener éxito. $Y$ aquí éxito no refiere a la aceptación de los proyectos eólico, solares, geotérmicos o renovables en general que sean propuestos a las comunidades, sino a aprovechar las situaciones de desacuerdo para enriquecer no solo el proyecto sino también y sobre todo la potencialidad ética de los actores, incluso si esto significa la cancelación de los proyectos en cuestión. 


\section{Agradecimientos}

Manuel Tironi agradece el apoyo del Proyecto FONDECYT N ${ }^{\circ} 1150319$ y del Centro de Investigación para la Gestión Integrada de Desastres Naturales (CIGIDEN), Conicyt/FONDAP/15110017.

Jorgelina Sannazzaro agradece el apoyo del Proyecto FONDECYT N ${ }^{\circ} 3160355$.

\section{NOTAS}

1. Jefes de comunidades mapuche.

2. El pueblo Huilliche o Williche ('gente del sur' en mapudungun) es la rama austral del pueblo mapuche. Habitan principalmente en las regiones de Los Ríos y de Los Lagos.

3. A través de estudios anteriores el BID ha identificado los déficits que impiden el surgimiento del deseado "empresario indígena": "(i) falta de información sobre los mercados potenciales; (ii) inexperiencia en la elaboración de planes de negocios; (iii) capacidades de gestión limitadas; (iv) esquemas de gobernanza económica incompletos; y (v) limitada valoración de los activos disponibles y de su potencial utilización" (PAEIBID 2016, 3).

4. Posteriormente el trabajo de estos consultores fue auditado y puesto en cuestionamiento, lo que probablemente precipitó el traspaso del proyecto a CORFO (se describe más adelante).

5. Las familias que integran cada una de las 17 comunidades de Huillinco-Cucao deben decidir su participación en el proyecto. Las comunidades concernidas son: 1. Catricura, 2. Quipulli, 3. Nalhuitad, 4. Chanquinpalihue, 5. Rahue, 6. La Montaña, 7. Quilpe, 8. Quiao, 9. Coipo, 10. Huillinco Alto, 11. Huentemo, 12. Chaique Cole-cole, 13. Chanquin, 14. Cucao, 15. Rahue-La Montaña, 16. Leuquetro y 17. Cahuala.

6. Tentativamente se propuso el nombre de "Sociedad de Energía Indígena de Chiloé" - SEICH.

7. EI PAEI-BID estableció que el financiamiento total del proyecto estaba compuesto por los servicios y activos necesarios para la puesta en marcha de este: 1 . El valor del territorio donde se instalan los molinos y las torres;

\section{RefERENCIAS Bibliográficas}

BID, Banco InterAmericano de Desarrollo. 2016. Programa de Desarrollo y Fomento Indígena. Recuperado de http://www.iadb.org/es/proyectos/project-informationpage, 1303.html?id=CH-L1105

Blaser, M. 2016. "Is Another Cosmopolitics Possible?" Cultural Anthropology 31(4): 545-570. http://doi.org/10.14506/ ca31.4.05

Boccara, G. y P. Bolados. 2010. "¿Qué es el multiculturalismo? La nueva cuestión étnica en el Chile neoliberal". Revista de Indias 70(250): 651-690. https://dx.doi. org/10.3989/revindias.2010.021

Bonelli, C. 2012. "Ontological Disorders: Nightmares, Psychotropic Drugs and Evil Spirits in Southern Chile". Anthropological Theory 12(4): 407-26. http://doi. org/10.1177/1463499612469587
2. El costo de los estudios técnicos del viento; 3. El costo de otros estudios (ej. estudio de producción, estudio de acceso a las redes eléctricas existentes en la isla de Chiloé); 4. El costo del estudio de impacto ambiental (en busca de financiación); 5. Que las comunidades del territorio analicen, socialicen y consulten la participación en el proyecto para dar cumplimiento al convenio 169 de la OIT en referencia al consentimiento previo libre e informado.

8. Institución gubernamental de apoyo al emprendimiento y la innovación para mejorar la productividad de Chile, a través de diversos programas de apoyo al emprendedor.

9. Es por esto, dice Derrida, que los principios éticos se prometen, y no se vaticinan o predicen.

10. La FCch, por ejemplo, no está organizada bajo la figura de autoridad del Cacique, similar a Lonko de los mapuche continentales.

11. El proyecto "Parque Eólico Chiloé" ubicado en Mar Brava ha generado una fuerte división en las comunidades locales. Las campañas de oposición son impulsadas principalmente por ONG ambientalistas, tales como Centro de Estudio y Conservación del Patrimonio Natural, Centro de Conservación Cetácea y algunos grupos indígenas. En el año 2012 la resolución de calificación ambiental de este proyecto fue revocada por la Corte Suprema, por no cumplimiento del proceso de consulta indígena considerada en el Convenio 169 de la Organización Internacional de Trabajo. El proyecto fue presentado nuevamente y aprobado por el SEIA en septiembre 2015, por lo que las comunidades opositoras presentaron recursos de amparo para su reconsideración.

Braun, K. y S. Schultz. 2009. “'... a Certain Amount of Engineering Involved': Constructing the Public in Participatory Governance Arrangements". Public Understanding of Science 19(4): 403-419. http://doi. org/10.1177/0963662509347814

Cadena, M. de la 2015. Earth Beings: Ecologies of Practice across Andean Worlds.

Campos, L. 2002. "La problemática indígena en Chile. De las políticas indígenas a la autonomía cutural". Revista de la academia 2: 39-58.

Chapman, C. 2013. "Multinatural Resources: Ontologies of Energy and the Politics of Inevitability in Alaska". Pp. 96-109 en Cultures of energy: Power, practices, technologies, editado por S. Strauss, S. Rupp, and T. F. Love. New York y London: Routledge. 
Colebrook, C. 2016. What Is the Anthropo-Political? Pp. 81125 en Twilight of the Anthropocene Idols, editado por T. Cohen, C. Colebrook y J. H. Miller. London: Open Humanities Press.

CONADI. 2008. Informe de la Comisión Verdad Histórica y Nuevo Trato con los Pueblos Indígenas. Recuperado de http:// www.memoriachilena.cl/602/articles-122901_recurso_2.pdf

Devine-Wright, P. 2014. Renewable Energy and the Public: From NIMBY to Participation. London: Routledge.

Deleuze, G. y F. Guattari. 2000. Mil mesetas. Capitalismo y esquizofrenia. Valencia: Pre-Textos.

Derrida, J. 1993. Specters of Marx: The State of the Debt, The Work of Mourning \& the New International Mendeley. London: Routledge Classics.

Felt, U. y M. Fochler. 2010. "Machineries for Making Publics: Inscribing and De-Scribing Publics in Public Engagement". Minerva 48(3): 219-238. http://doi.org/10.1007/ s11024-010-9155-x

Gross, M. 2015. "Give Me an Experiment and I Will Raise a Laboratory". Science, Technology, \& Human Values 41(4): 613-34. http://doi.org/10.1177/0162243915617005

Haraway, D. 2016. Staying with the Trouble: Making Kin in the Chthulucene. Durham: Duke University Press.

Hinchliffe, S. 2007. Geographies of nature, societies, environments, ecologies. London: Sage.

Horvath-Kiss, A. 2015. La revolución de los territorios y de las energías. Santiago de Chile: LOM.

Howe, C. y D. Boyer. 2015. "Aeolian Politics". Distinktion: Journal of Social Theory 16(1): 31-48. http://dx.doi.or $\mathrm{g} / 10.1080 / 1600910 X .2015 .1022564$

Jasanoff, S. 2004. States of Knowledge: The Co-Production of Science and Social Order. London, UK: Routledge.

Knorr-Cetina, K. D. 1981. The Manufacture of Knowledge. An Essay on the Constructivist and Contextual Nature of Science. Pennsylvania, Philadelphia: Pergamon Press Ltd.

Latour, B. 1988. The Pasteurization of France. Cambridge, Massachusetts: Harvard University Press.

Latour, B and S. Woolgar. 1979. Laboratory Life: The Construction of Scientific Facts. Beverly Hills: SAGE publications.

Latour, B. 2004. "Whose Cosmos, Which Cosmopolitics? Comments on the Peace Terms of Ulrich Beck". Common Knowledge 10(3): 450-462. http://doi. org/10.1215/0961754X-10-3-450

Lezaun, J. 2007. "A Market of Opinions: The Political Epistemology of Focus Groups". Sociological Review 55(2): 13051. http://doi.org/10.1111/j.1467-954X.2007.00733.x

Lezaun, J. y L. Soneryd. 2007. "Consulting Citizens: Technologies of Elicitation and the Mobility of Publics". Public Understanding of Science 16(3): 279-97. http://doi. org/10.1177/0963662507079371

Lezaun, J., N. Marres y M. Tironi. 2016. "Chapter 7: Experiments in Participation". Pp. 195-222 en The Handbook of Science and Technology Studies (Fourth ed.). Cambridge, MA: MIT Press.

Marres, N. 2012. Material Participation. Technology, the Environment and Everyday Publics. London, UK: Palgrave Macmillan.

Michael, Mike. 2009. "Publics Performing Publics: OfPiGs, PiPs and Politics". Public Understanding of Science 18(5): 617-31. http://doi.org/10.1177/0963662508098581

Mol, A. 2002. The Body Multiple: Ontology in Medical Practice. Durham, UK: Duke University Press.

Muniesa, F. y M. Callon. 2007. "Economic Experiments and the Construction of Markets". Pp. 163-189 en Do eco- nomists make markets? On the performativity of economics, editado por D. MacKenzie, F. Muniesa y L. Siu. Princeton, NJ: Princeton University Press.

Newbold, K. y M. Foulkes. 2004. "Geography and Segmented Assimilation: Examples from the New York Chinese". Population, Space and Place 10(1): 3-18. http://doi. org/10.1002/psp.301

Povinelli, E. 2011. Economies of Abandonment: Social Belonging and Endurance in Late Liberalism. Durham, NC: Duke University Press.

Puig de la Bellacasa, M. 2011. "Matters of Care in Technoscience: Assembling Neglected Things". Social studies of science 41(1): 85-106. http://doi. org/10.1177/0306312710380301

Rancière, J. 1996. El desacuerdo. Política y filosofía. Buenos Aires: Nueva Visión.

Rheinberger, H-J. 1997. Toward a History of Epistemic Things: Synthesizing Proteins in the Test Tube. Stanford: Stanford University Press.

Rose, N. 1999. Powers of Freedom: Reframing Political Thought. Cambridge: Cambridge University Press.

Schillmeier, M. 2011. "Unbuttoning Normalcy - on Cosmopolitical Events". The Sociological Review 59(3): 514-534. http://doi.org/10.1111/j.1467-954X.2011.02019.x

Shapin, S. y S. Schaffer. 1989. Leviathan and the Air-Pump: Hobbes, Boyle, and the Experimental Life. Princeton: Princeton University Press.

Star, S. L. y J.R. Griesemer. 1989. "Institutional Ecology, 'Translations' and Boundary Objects: "Amateurs and Professionals in Berkeley's Museum of Vertebrate Zoology, 1907-39". Social Studies of Science 19 (3): 387-420.

Stengers, I. 2000. The Invention of Modern Science. Minneapolis: University of Minnesota Press.

Stengers, I. 2005. "The cosmopolitical proposal". Pp. 9941003 en Making Things Public, editado por B. Latour y P. Weibel. Cambridge, MA: MIT Press.

Tironi, M. 2014. "Atmospheres of indagation: disasters and the politics of excessiveness". Sociological Review 62(S1): 114-134. http://doi.org/10.1111/1467-954X.12126

Tironi, M. 2015. "Disastrous Publics: counter-enactments in participatory experiments". Science, Technology \& Human Values 40(4): 564-87. http://doi. org/10.1177/0162243914560649

Tironi, M. 2016. Ningún acuerdo possible: conflictos, diferencia radical y política especulativa.Pp. 131-181 en Conflictos, controversias y disyuntivas, editado por Araya, R. y F. Ceballos. Santiago de Chile: ABIERTA.

Tironi, M. y J. Barandiaran. 2014. "Neoliberalism as political technology: expertise, energy and democracy". Pp. 305-330 en Beyond Imported Magic: Studying Science and Technology in Latin America in Chile, editado por C. Medina, I. Costa Márques y C. Holmes. Cambridge: MIT Press.

Tsing, A. 2011. Friction: An Ethnography of Global Connection. Princeton University Press.

Vergara, J. I., R. Foerster y H. Gundermann. 2005. "Instituciones mediadoras, legislación y movimiento indígena de DASIN a CONADI (1953-1994)“. Atenea (Concepción) 491: 71-85.

Viveiros De Castro, E. 2004. "Perspectival Anthropology and the Method of Controlled Equivocation". Tipiti: Journal of the Society for the Anthropology of Lowland South America 2(1): 2-22. Recuperado de http://digitalcommons.trinity.edu/tipiti/vol2/iss $1 / 1 /$ 
MANUEL TIRONI es profesor asociado en el Instituto de Sociología de la Pontificia Universidad Católica de Chile e investigador asociado en el Núcleo Milenio de Investigación en Energía y Sociedad, NUMIES, y en el Centro de Investigación para la Gestión Integrada de Desastres, CIGIDEN. Su agenda de investigación gira en torno a temas de ecología, desastres, teoría social y estudios de la ciencia y tecnología. Su trabajo ha sido publicado en Sociological Review, Science Technology \& Human Values y Geoforum, entre otras revistas, y su libro Disasters and Politics: Materials, Experiments, Preparedness (Wiley-Blackwell, 2014, co-editado junto a I. Rodríguez-Giralt y M. Guggenheim) ganó el Amsterdamska Award 2015 entregado por la European Association for the Study of Science and Technology. Ha sido profesor visitante en las Universidades de Warwick y Goldsmiths, University of London.

JORGELINA SANNAZZARO, Doctora en Estudios Sociales de la Ciencia y la Tecnología de la Universidad de Salamanca, España. Actualmente es investigadora posdoctoral y profesora de la Universidad Alberto Hurtado (Chile). Ejerció como investigadora del Instituto de Estudios de Ciencia y Tecnología de la Universidad de Salamanca, España (2009 - 2015) e investigadora visitante del Instituto de Estudios del Desarrollo y Steps- Sussex, Brighton (2014). Se graduó en Psicología en 2007 en la Universidad Nacional de Rosario - Argentina (UNR) y ejerció entre 2000 a 2008 como auxiliar de investigación en el Centro de Investigación y Desarrollo Social - UNR. Su investigación actual se centra en la participación pública en los conflictos socio-ambientales, la política energética, ciencia y democracia. 